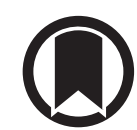

CrossMark

\title{
Implementing lung health interventions in low- and middle-income countries: a FRESH AIR systematic review and meta-synthesis
}

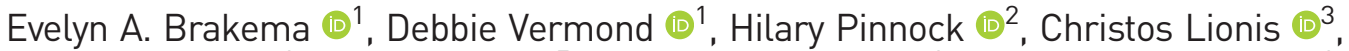 \\ Bruce Kirenga (10 ${ }^{4}$, Pham Le An (10) ${ }^{5}$, Talant Sooronbaev (10) ${ }^{6}$, Niels H. Chavannes (1) ${ }^{1}$ \\ and M. J. J. Rianne van der Kleij ${ }^{1}{ }^{1}$ on behalf of the FRESH AIR collaborators
}

@ERSpublications

This systematic review and meta-synthesis shows why implementation of lung health interventions often fails in low- and middle-income countries, and it provides critical factors to prevent failure with their level of evidence https://bit.ly/2UYJOSa

Cite this article as: Brakema EA, Vermond D, Pinnock H, et al. Implementing lung health interventions in low- and middle-income countries: a FRESH AIR systematic review and meta-synthesis. Eur Respir J 2020; 56: 2000127 [https://doi.org/10.1183/13993003.00127-2020].

ABSTRACT The vast majority of patients with chronic respiratory disease live in low- and middle-income countries (LMICs). Paradoxically, relevant interventions often fail to be effective particularly in these settings, as LMICs lack solid evidence on how to implement interventions successfully. Therefore, we aimed to identify factors critical to the implementation of lung health interventions in LMICs, and weigh their level of evidence.

This systematic review followed Cochrane methodology and Preferred Reporting Items for Systematic Review and Meta-Analyses (PRISMA) reporting standards. We searched eight databases without date or language restrictions in July 2019, and included all relevant original, peer-reviewed articles. Two researchers independently selected articles, critically appraised them (using Critical Appraisal Skills Programme (CASP)/ Meta Quality Appraisal Tool (MetaQAT)), extracted data, coded factors (following the Consolidated Framework for Implementation Research (CFIR)), and assigned levels of confidence in the factors (via Grading of Recommendations Assessment, Development and Evaluation-Confidence in the Evidence from Reviews of Qualitative research (GRADE-CERQual)). We meta-synthesised levels of evidence of the factors based on their frequency and the assigned level of confidence (PROSPERO:CRD42018088687).

We included 37 articles out of 9111 screened. Studies were performed across the globe in a broad range of settings. Factors identified with a high level of evidence were: 1) "Understanding needs of local users"; 2) ensuring "Compatibility" of interventions with local contexts (cultures, infrastructures); 3) identifying influential stakeholders and applying "Engagement" strategies; 4) ensuring adequate "Access to knowledge and information"; and 5) addressing "Resource availability". All implementation factors and their level of evidence were synthesised in an implementation tool.

To conclude, this study identified implementation factors for lung health interventions in LMICs, weighed their level of evidence, and integrated the results into an implementation tool for practice. Policymakers, nongovernmental organisations, practitioners, and researchers may use this FRESH AIR (Free Respiratory Evaluation and Smoke-exposure reduction by primary Health cAre Integrated gRoups) Implementation tool to develop evidence-based implementation strategies for related interventions. This could increase interventions' implementation success, thereby optimising the use of already-scarce resources and improving health outcomes.

This article has supplementary material available from erj.ersjournals.com

The FRESH AIR study is registered under trial registration number: NTR5759 (http://www.trialregister.nl/trialreg/admin/ rctsearch.asp?Term=23332). All data and meta-data can be shared upon reasonable request. This includes among others the study protocol and meeting minutes describing considerations for data analysis. Within reasonable time after email request, data will be shared via a secure web-based system.

Received: 21 Jan 2020 | Accepted after revision: 29 March 2020

Copyright $\odot$ ERS 2020. This article is open access and distributed under the terms of the Creative Commons Attribution Non-Commercial Licence 4.0. 


\section{Introduction}

Chronic respiratory diseases (CRDs) are a silent and growing epidemic in low- and middle-income countries (LMICs). Chronic obstructive pulmonary disease (COPD) is now the third leading cause of death worldwide; over $90 \%$ of these deaths and $80 \%$ of asthma-related deaths occur in LMICs [1-5]. LMICs are disproportionately burdened by CRDs because of the early and high exposure to risk factors for lung impairment [6-13]. Suboptimal access to diagnostic and treatment options in LMICs additionally exacerbates disease severity $[6,11]$. Although promising interventions targeting CRD have existed for decades, many fail to translate into meaningful health outcomes. The disappointing intervention effects are often attributed to implementation failure [14-18]. In some estimates, over $60 \%$ of organisations' implementation efforts are unsuccessful [19]. Implementation success of clean cookstove programmes is often reported as strikingly low, with stove adoption rates of $4-10 \%$ [20-25].

However, implementation, the act of carrying an intervention into effect [26], is complex. Throughout the entire implementation process, from the dissemination of an intervention to its sustained use [27], numerous factors determine success or failure. These implementation factors are often interacting and influential at multiple levels. To better understand the factors so that they can be adequately addressed in implementation strategies, factors can be pragmatically structured. The Consolidated Framework for Implementation Research (CFIR) integrated 42 implementation factors from existing implementation theories [18], and categorised them in five domains: 1) innovation characteristics (e.g. the adaptability of an intervention); 2) outer setting (e.g. understanding the needs of local users); 3) inner setting (e.g. resource availability); 4) characteristics of individuals (e.g. self-efficacy); and 5) process (e.g. engagement of stakeholder). The importance of each factor depends on the context [28, 29]. Hence, implementation strategies are more successful when context-specific factors are known and addressed.

Therefore, it is essential to understand which specific factors play a role in the context of CRDs in LMICs. Paradoxically, despite the highest burden of CRD in LMICs, precisely in these countries, evidence on what factors determine implementation success is limited, fragmented and of varying methodological quality [30-33]. Extrapolating the evidence from high-income countries to LMICs is inappropriate because of differences in health, economic and cultural contexts. Several calls already highlighted the need for high-quality implementation research in LMICs [25, 34-37]. Therefore, in this study, we aimed to identify factors critical to the successful implementation of interventions targeting CRDs in LMICs, and to weigh their level of evidence.

\section{Methods}

This systematic review and meta-synthesis is part of the Horizon2020 FRESH AIR project (Free Respiratory Evaluation and Smoke-exposure reduction by primary Health cAre Integrated gRoups), addressing the implementation of prevention, diagnosis, and treatment of CRD in low-resource settings (trial registration number: NTR5759) [38]. This review is registered at PROSPERO (CRD42018088687) and follows Cochrane methodology $[39,40]$ and the Preferred Reporting Items for Systematic Review and Meta-Analyses (PRISMA) reporting standards [41].

All steps of the review process were performed by two researchers (E.A. Brakema and D. Vermond) independently. Results were compared, and discrepancies solved through discussion. A third researcher (R.M.J.J. van der Kleij) was consulted when consensus could not be reached. We systematically applied validated tools throughout the entire process, to enhance the reproducibility and transparency of our outcomes (figure 1).

\section{Search strategy and selection criteria}

We developed the search strategy together with a certified medical librarian; it contained (synonyms of) implementation, LMICs and CRD or specific relevant interventions such as "smoking cessation" (appendix 1). We focussed on asthma and COPD as the most prevalent chronic lung diseases. In PubMed, Embase, Global Health Database, Cochrane, PsycINFO, Emcare, Web of Science and CINAHL, we searched

Affiliations: ${ }^{1}$ Dept of Public Health and Primary Care, Leiden University Medical Center, Leiden, The Netherlands. ${ }^{2}$ NIHR Global Health Research Unit on Respiratory Health (RESPIRE), Usher Institute of Population Health Sciences and Informatics, The University of Edinburgh, Edinburgh, UK. ${ }^{3}$ Clinic of Social and Family Medicine, School of Medicine, University of Crete, Heraklion, Greece. ${ }^{4}$ Dept of Medicine and Makerere Lung Institute, Makerere University, Kampala, Uganda. ${ }^{5}$ Center of Training Family Medicine, University of Medicine and Pharmacy, Ho Chi Minh City, Vietnam. ${ }^{6}$ Pulmonary Dept, National Center of Cardiology and Internal Medicine, Bishkek, Kyrgyzstan.

Correspondence: Evelyn A. Brakema, Dept of Public Health and Primary Care, Leiden University Medical Center, Postzone V0-P, Postbus 9600, 2300 RC, Leiden, The Netherlands. E-mail: evelynbrakemadagmail.com 


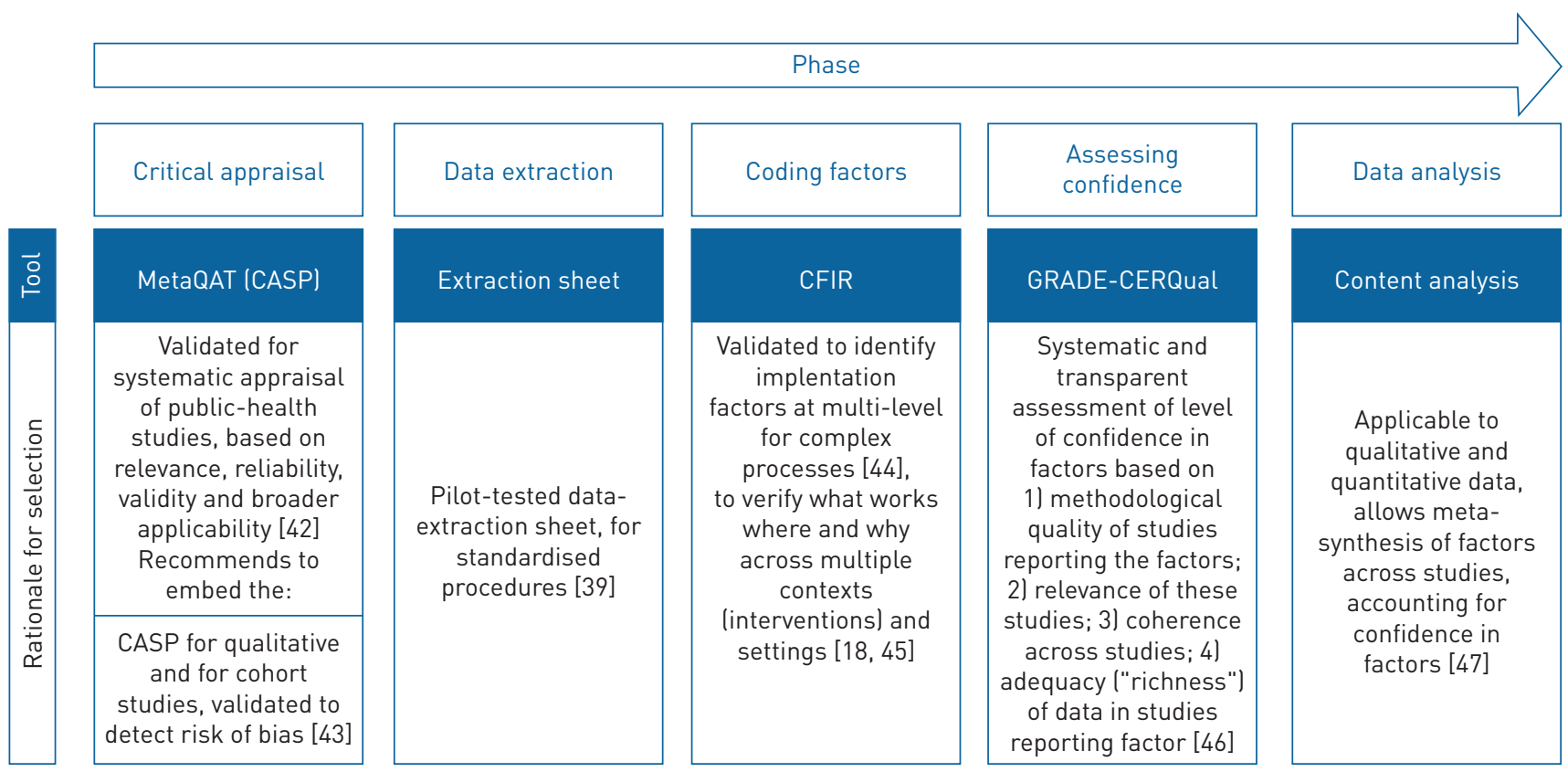

FIGURE 1 Tool used in each phase. Meta-QAT: Meta Quality Appraisal Tool; CASP: Critical Appraisal Skills Programme; CFIR: Consolidated Framework for Implementation Research; GRADE-CERQual: Grading of Recommendations Assessment, Development and Evaluation-Confidence in the Evidence from Reviews of Qualitative research.

without language restriction for articles published by Oct 23, 2017, and updated our search on July 10, 2019. We included all relevant, original, peer-reviewed articles focussing on the implementation of interventions targeting CRD in LMICs (as classified by the World Bank [48]). As recommended for studying implementation, quantitative, qualitative and mixed-method articles were considered relevant [26]. Articles were excluded if they focussed on legislation at a national governmental level (e.g. implementation of tobacco taxes) or on hypothetical interventions (e.g. theoretical willingness to adopt an intervention), if no factors were reported, or if no full text was available after contacting the authors. Our orienting search resulted in a disproportionate number of articles on the implementation of clean cooking interventions targeting household air pollution. To avoid this specific intervention dominating all review findings, we decided to split our review into two parts. This first review regards the implementation of all but clean cooking interventions, while the second (to be published later) will be exclusively dedicated to those.

Full operationalisation of the search criteria is presented in appendix 1. In addition, we manually searched Google and Google Scholar for the full articles from identified conference abstracts and study protocols, and screened all references from relevant reviews and the included articles.

\section{Critical appraisal}

To critically appraise the included articles on relevance, reliability (reporting quality), validity and applicability, we used the validated Meta Quality Appraisal Tool (MetaQAT) [42] (appendix 2) and, as recommended, we embedded the Critical Appraisal Skills Programme (CASP) into it [43]. Results served as input for the assessment of level of evidence of the identified factors (see data analysis).

\section{Data extraction}

We extracted descriptive study characteristics (author, year, study design, country, setting/population, intervention, type of outcomes measures used and funding source) and the implementation factors using a pilot-tested, standardised sheet. Speculations (such as "Factor A might have influenced implementation") or repetitions in the reporting of factors within the same article were not extracted. We extracted modifiable factors (e.g. factors to address user demographics would be extracted, but demographics on their own would not), to serve the design of future implementation initiatives. Only factors based on original data were extracted. If multiple articles were based on the same study, we compared the article's aim, methods and results in detail. If these were similar, we extracted data from the article that scored highest in our appraisal. If they differed (e.g. one was a pilot version and the other the scale-up of the same study), data from both (or more) articles were used. 


\section{Data analysis}

For our meta-synthesis (weighing of the factors) we used content analysis, in which all data are categorised into themes and the frequencies of the themes are determined. Content analysis is suitable for both qualitative and quantitative evidence [47].

First, we categorised all identified implementation factors by deductive coding using the CFIR [18]. We inductively added several codes to the CFIR (such as "language" or "role model") when our extracted factors did not match existing codes (appendix 3). Second, we used the Grading of Recommendations Assessment, Development and Evaluation-Confidence in the Evidence from Reviews of Qualitative research (GRADE-CERQual) tool to determine the level of confidence in the importance of the coded factors. The GRADE-CERQual tool has four components (figure 1), and the results of the critical appraisal served as input for scoring those (e.g. a high MetaQAT score for relevance translated into "no to very minor concerns" in the GRADE-CERQual component "relevance") [46]. Third, each factor was awarded a maximum of four points per component per study in which it appeared (four points for "no to very minor concerns" regarding the component in that specific study, three for "minor concerns", two for "moderate concerns", and one for "substantial concerns"). Hence, factors were awarded higher scores when they appeared in more studies (the principle of content analysis), and when the components methodology, relevance and adequacy of the study were appraised as high. The fourth GRADE-CERQual component "coherence" was not rated, because the number of studies in which the factor appeared already accounted for coherence. To conclude, the higher a factor scored, the higher the level of evidence to regard it as an important factor.

\section{Role of the funding source}

This study was funded by the European Union Research and Innovation programme Horizon2020 (Health, Medical research and the challenge of ageing) under grant agreement no. 680997. The funders had no role in study design, data collection, data analysis, data interpretation or writing of the report. All authors had full access to all the data and E.A. Brakema, D. Vermond, R.M.J.J. van der Kleij and N.H. Chavannes, the guarantor, had the final responsibility for the decision to submit the study for publication.

\section{Reflexivity}

Members of our research team came from diverse backgrounds (researchers and clinicians from psychology and medicine, with work experience in high-income countries, LMICs, or both). In these roles, we had experienced working conditions characterised by many of the factors we identified, such as lack of resources and personnel. We recognised that we were potentially more receptive to factors we had experienced ourselves, so adhered to our standardised extraction procedures.

\section{Results}

\section{Search results}

Our search resulted in 9111 unique articles. After full-text screening, we included 37 articles derived from 33 different studies (figure 2 and table 1). One article was excluded from the analysis [49], as its factors were based on the exact same study data as another article which scored higher in the critical appraisal [50].

\section{Study characteristics}

The studies resulting from our search were conducted in 17 different LMICs across five geographical regions: Latin America (Brazil [51-55], the Dominican Republic [56], Mexico [57], Surinam [58]), Africa (Malawi [59], South Africa [60-62]), the Middle East (Lebanon [63], Syria [64]), Asia (China [65-69], India [49, 50, 70-75], Indonesia [73, 76], Malaysia [77], Nepal [78, 79], Pakistan [80], Russia [81], Thailand [82-83]) and Oceania (Fiji [85]) (table 1 and figure 3). Most studies were based in healthcare settings $(n=17$; primary care $(n=9)$, secondary care $(n=5)$, primary/secondary care combined $(n=3))$, followed by schools $(n=13)$, and the community $(n=6)$. The majority of the study interventions focussed on tobacco $(n=27$; cessation $(n=10)$, prevention $(n=8)$, both $(n=2)$ and control (i.e. smoking-free setting) $(n=7)$ ). Three studies focussed on interventions to improve the implementation of guidelines. One study focussed on quality improvement of COPD management, one on delivery of integrated asthma/COPD care, and one on the adaptation of post-partum rituals using biomass smoke to "protect" newborns. Three articles used quantitative methods for determining implementation factors, 31 used qualitative methods, and two used both.

\section{Critical appraisal of the studies}

The quality of the articles varied: 19 articles scored high in the MetaQAT on relevance to the research question, 17 scored medium and one scored low (table 1, and for further details appendix 4). Articles scored variably on reliability (15 high, 11 medium, $11 \mathrm{low}$ ) and the lower scores were often due to unclear 
reporting of methods. Data analyses and researcher reflexivity were particularly poorly reported in many qualitative articles, which affected the reproducibility and transparency (thus validity). 12 articles scored high on validity, 10 scored medium, one scored low and for 14 articles validity was unclear.

\section{Implementation factors}

45 implementation factors were identified, with a large variation in factors' levels of evidence (appendix 5). The factors with the highest level of evidence are described in further detail below, these belonged to CFIR domains "Process", "Inner setting" and "Outer setting" (figure 4). A full overview of all weighed factors, their definitions and illustrations of how they occurred in the included studies is detailed in appendix 6.

"Engaging", "attracting and involving appropriate individuals in the implementation and use of the innovation (...)" [18], in the domain "Process" was coded 72 times across 29 articles. Identifying influential stakeholders before and during the implementation process, and developing effective engagement strategies was often reported as "crucial". Moreover, authors stated that the context determined who was considered as influential. The articles addressed relevant deliverers (e.g. teachers, staff, health workers), potential collaborators (e.g. government officials, village leaders or other authorities who could block implementation if not successfully engaged) and recipients of the intervention (e.g. "all villagers at once" versus "initially only highly respected villagers") as important stakeholders to consider. Among a broad range of reported strategies, engagement was frequently established after gaining trust and commitment from the participants, and when a sense of ownership was created (e.g. through participatory approaches). Equally, failure to engage stakeholders was attributed to the lack of engagement activities, e.g. demotivation of intervention recipients due to lack of ongoing communication.

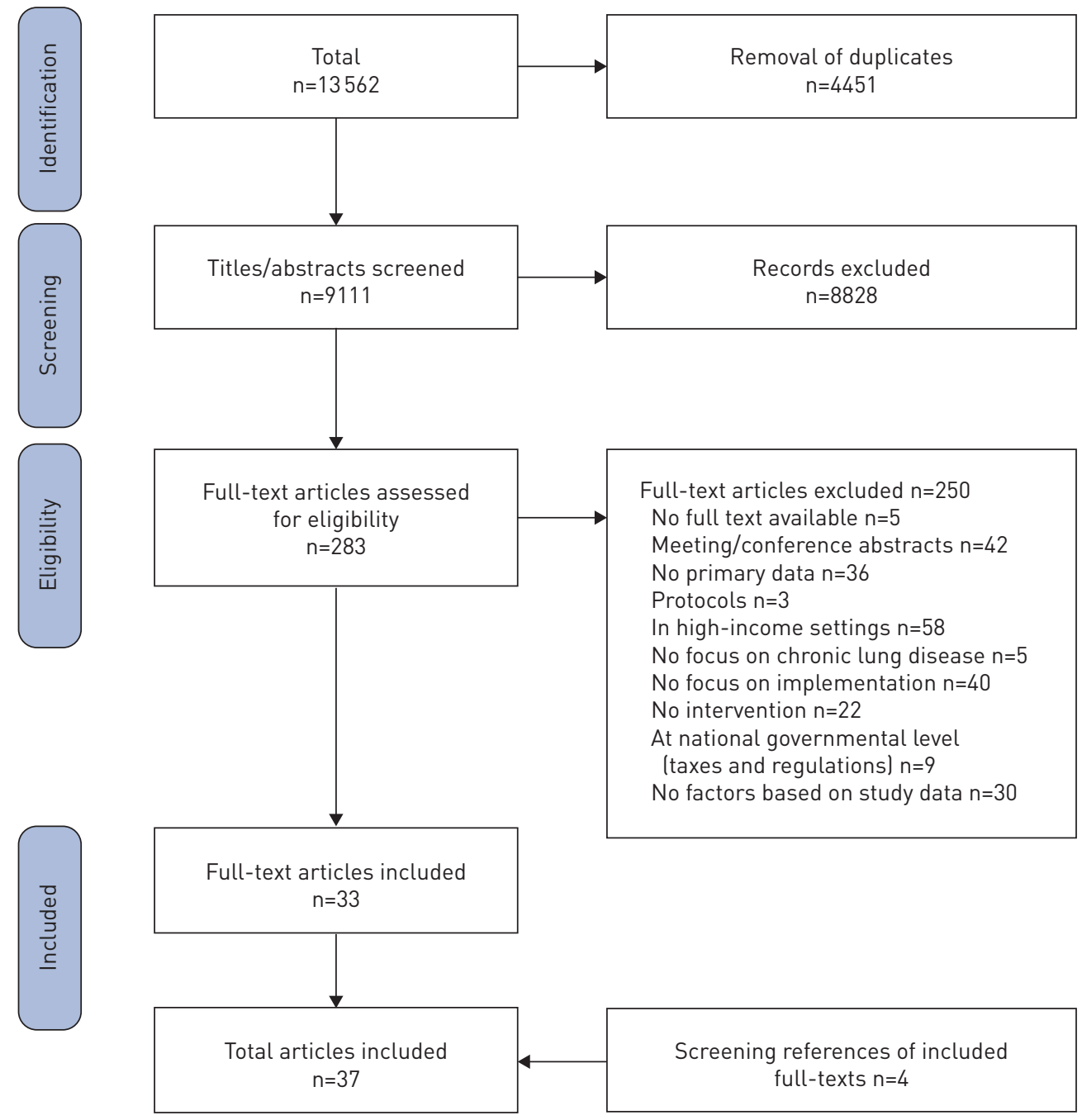

FIGURE 2 Flow diagram of screening process. 
TABLE 1 Characteristics of the included studies and critical appraisal, by author

\begin{tabular}{|c|c|c|c|c|c|c|c|c|}
\hline \multirow[t]{2}{*}{ First author [ref.] } & \multirow[t]{2}{*}{ Study design } & \multirow[t]{2}{*}{ Country } & \multirow[t]{2}{*}{ Setting; population } & \multirow[t]{2}{*}{ Intervention } & \multicolumn{4}{|c|}{$\begin{array}{c}\text { Summary of } \\
\text { appraisal }\end{array}$} \\
\hline & & & & & Rv & $\mathbf{R}$ & V & A \\
\hline ALDINGER [66]" & $\begin{array}{l}\text { Qualitative (institutional } \\
\text { ethnographyl }\end{array}$ & China & $\begin{array}{l}\text { Primary to vocational } \\
\text { schools; } \\
\text { administrators, staff, } \\
\text { teachers, students and } \\
\text { parents }\end{array}$ & $\begin{array}{l}\text { Tobacco prevention } \\
\text { within } \\
\text { programme of } \\
\text { health-promoting } \\
\text { schools }\end{array}$ & - & + & \pm & + \\
\hline $\begin{array}{l}\text { ASSANANGKORNCHAI } \\
\text { [82] }\end{array}$ & $\begin{array}{l}\text { Qualitative laction } \\
\text { research) }\end{array}$ & Thailand & $\begin{array}{l}\text { Primary healthcare } \\
\text { setting; healthcare } \\
\text { workers (nurses, } \\
\text { administrators, } \\
\text { directors) }\end{array}$ & $\begin{array}{l}\text { Tobacco, alcohol } \\
\text { and substance } \\
\text { use screening } \\
\text { and brief } \\
\text { intervention }\end{array}$ & \pm 1 & \pm & \pm & + \\
\hline BHEEKIE [60] & $\begin{array}{l}\text { Qualitative study } \\
\text { preparing for an RCT }\end{array}$ & South Africa & $\begin{array}{l}\text { Primary healthcare } \\
\text { setting; trained nurses, } \\
\text { with a supervisory } \\
\text { position as care } \\
\text { coordinators }\end{array}$ & $\begin{array}{l}\text { Train-the-trainer } \\
\text { programme on } \\
\text { implementation } \\
\text { of respiratory } \\
\text { guidelines on } \\
\text { (obstructive) lung } \\
\text { diseases }\end{array}$ & + & + & + & \pm \\
\hline ChatterJee [70] & Qualitative & India & $\begin{array}{l}\text { Rural villages; } \\
\text { community members } \\
\text { (programme } \\
\text { managers, } \\
\text { coordinators, health } \\
\text { workers and } \\
\text { stakeholders at village } \\
\text { level) }\end{array}$ & Tobacco-free village & +1 & \pm & \pm & + \\
\hline CRUVINEL [52] & $\begin{array}{l}\text { Quantitative, survey } \\
\text { design (correlations) }\end{array}$ & Brazil & $\begin{array}{l}\text { Urban, primary } \\
\text { healthcare; } 149 \\
\text { diverse workers (e.g. } \\
\text { community health } \\
\text { workers, nurses, } \\
\text { physicians) }\end{array}$ & $\begin{array}{l}\text { Training on tobacco, } \\
\text { alcohol and drug } \\
\text { use screening } \\
\text { and brief } \\
\text { intervention }\end{array}$ & \pm & + & + & \pm \\
\hline
\end{tabular}


TABLE 1 Continued

First author [ref.]

Study design

Country

Setting; population

Intervention

Summary of

appraisal

\begin{tabular}{|c|c|c|c|c|c|c|c|c|}
\hline & & & & & Rv & $\mathbf{R}$ & v & A \\
\hline ELSEY [78] & $\begin{array}{l}\text { Mixed-method, factors } \\
\text { derived from qualitative } \\
\text { data (action research) }\end{array}$ & Nepal & $\begin{array}{l}\text { Urban and rural primary } \\
\text { healthcare; patients, } \\
\text { healthcare providers, } \\
\text { managers and policy } \\
\text { makers }\end{array}$ & $\begin{array}{l}\text { Tobacco cessation, } \\
\text { behaviour support }\end{array}$ & +1 & + & + & + \\
\hline GoENKA $[71]^{+}$ & $\begin{array}{l}\text { Mixed-method study } \\
\text { within an RCT }\end{array}$ & India & $\begin{array}{l}32 \text { Urban, public and } \\
\text { private schools; } \\
\text { professionals with a } \\
\text { Master's degree in } \\
\text { psychology, sociology } \\
\text { or nutrition who taught } \\
\text { teachers and peer } \\
\text { leaders }\end{array}$ & $\begin{array}{l}\text { Tobacco prevention } \\
\text { by teachers and } \\
\text { peer-leaders }\end{array}$ & \pm & + & \pm & \pm \\
\hline GROTH-MARNAT [85] & Qualitative & Fiji & $\begin{array}{l}\text { Traditional village; } \\
\text { community members }\end{array}$ & Tobacco cessation & +1 & \pm & $?$ & \pm \\
\hline MALAN [61] & Qualitative & South Africa & $\begin{array}{l}\text { Primary care practice; } \\
\text { care providers (nurses } \\
\text { and physicians) }\end{array}$ & $\begin{array}{l}\text { Brief behaviour } \\
\text { change } \\
\text { counselling } \\
\text { (“5As”] for } \\
\text { tobacco, diet, } \\
\text { physical activity } \\
\text { and alcohol } \\
\text { abuse }\end{array}$ & \pm 1 & + & + & + \\
\hline McAlister [81] & $\begin{array}{l}\text { Qualitative for the factors } \\
\text { reported, within a } \\
\text { quantitative study }\end{array}$ & Russia & $\begin{array}{l}\text { Community level; } \\
\text { hospital staff, } \\
\text { intervention for } \\
\text { community smokers }\end{array}$ & $\begin{array}{l}\text { Stop smoking } \\
\text { campaign }\end{array}$ & + & \pm & $?$ & \pm \\
\hline Medeiros [53] & $\begin{array}{l}\text { Mixed-methods, factors } \\
\text { derived from qualitative } \\
\text { data }\end{array}$ & Brazil & $\begin{array}{l}\text { Urban schools; teachers, } \\
\text { school administrators, } \\
\text { coaches, other } \\
\text { stakeholders le.g. } \\
\text { municipalityl and } \\
\text { students }\end{array}$ & $\begin{array}{l}\text { Tobacco prevention } \\
\text { within a drug use } \\
\text { prevention } \\
\text { programme }\end{array}$ & \pm & + & + & + \\
\hline
\end{tabular}


TABLE 1 Continued

First author [ref.]

Study design

Country

Setting; population

Intervention

Summary of

appraisal

\begin{tabular}{|c|c|c|c|c|c|c|c|c|}
\hline & & & & & & & & \\
\hline MEHANNI [79] & Qualitative & Nepal & $\begin{array}{l}\text { Small rural hospital } \\
\text { (managed through a } \\
\text { public-private } \\
\text { partnership) }\end{array}$ & $\begin{array}{l}\text { Quality } \\
\text { improvement } \\
\text { initiative for } \\
\text { management of } \\
\text { COPD }\end{array}$ & + & - & $?$ & \pm \\
\hline MeLson [77] & $\begin{array}{l}\text { Mixed-methods within } \\
\text { pilot RCT; factors } \\
\text { derived from qualitative } \\
\text { data (quantitative data } \\
\text { n.a., regard hypothetic } \\
\text { factors prior to } \\
\text { implementation). Pro- } \\
\text { and retrospective }\end{array}$ & Malaysia & $\begin{array}{l}\text { Secondary school; } \\
\text { students }\end{array}$ & $\begin{array}{l}\text { Peer-led } \\
\text { anti-smoking } \\
\text { intervention } \\
\text { (smoke-free } \\
\text { class) }\end{array}$ & +1 & + & + & + \\
\hline NAGLER $[72]^{\#}$ & $\begin{array}{l}\text { Qualitative, formative pilot } \\
\text { study preparing for an } \\
\text { RCT }\end{array}$ & India & $\begin{array}{l}\text { One public urban and } \\
\text { one rural school, not } \\
\text { included in the RCT; } \\
\text { health educators and } \\
\text { teachers }\end{array}$ & $\begin{array}{l}\text { Tobacco cessation - } \\
\text { school based }\end{array}$ & \pm & + & + & \pm \\
\hline Nichter [73] & Qualitative & $\begin{array}{l}\text { India \& } \\
\text { Indonesia }\end{array}$ & $\begin{array}{l}\text { Lead public \& private } \\
\text { medical schools and } \\
\text { outreach to their } \\
\text { communities }\end{array}$ & $\begin{array}{l}\text { Training network for } \\
\text { tobacco } \\
\text { prevention } \\
\text { (curricula), } \\
\text { outreach and } \\
\text { clinic on smoking } \\
\text { cessation }\end{array}$ & +1 & - & $?$ & \pm \\
\hline Ossip [56] & $\begin{array}{l}\text { Qualitative (Rapid } \\
\text { Assessment Process) }\end{array}$ & $\begin{array}{r}\text { Dominican } \\
\text { Republic }\end{array}$ & $\begin{array}{l}\text { Urban, peri-urban \& } \\
\text { rural communities } \\
\text { with active Community } \\
\text { Technology Centers; a } \\
\text { multidisciplinary team } \\
\text { including specialists of } \\
\text { psychology, } \\
\text { anthropology, nursing, } \\
\text { epidemiology, statistics } \\
\text { and public health } \\
\text { (from the US) and } \\
\text { medicine (DR) }\end{array}$ & $\begin{array}{l}\text { Tobacco cessation - } \\
\text { participatory } \\
\text { approach }\end{array}$ & +1 & \pm & $?$ & \pm \\
\hline Pereira [54] & $\begin{array}{l}\text { Quantitative, } \\
\text { population-based } \\
\text { cross-sectional survey } \\
\text { design }\end{array}$ & Brazil & $\begin{array}{l}\text { Urban public and private } \\
\text { schools; } 263 \text { school } \\
\text { managers } \\
\text { (headmasters, } \\
\text { pedagogical } \\
\text { coordinators, } \\
\text { coordinators of the } \\
\text { prevention } \\
\text { programmes) }\end{array}$ & $\begin{array}{l}\text { Tobacco prevention } \\
\text { within a drug use } \\
\text { prevention } \\
\text { programme }\end{array}$ & \pm 1 & + & \pm & \pm \\
\hline PerRy $[74]^{+}$ & $\begin{array}{l}\text { Qualitative study } \\
\text { (translational research) } \\
\text { within an RCT following } \\
\text { translational research }\end{array}$ & India & $\begin{array}{l}32 \text { urban schools, half } \\
\text { were public and half } \\
\text { were private; school } \\
\text { administration, } \\
\text { teachers, and } \\
\text { peer-leaders }\end{array}$ & Tobacco prevention & \pm 1 & - & $?$ & \pm \\
\hline PeRsal [75] & Qualitative & India & $\begin{array}{l}\text { At district level; senior } \\
\text { district officials }\end{array}$ & Tobacco control & \pm 1 & + & + & + \\
\hline
\end{tabular}


TABLE 1 Continued

First author [ref.]

Study design

Country

Setting; population

Intervention

Summary of

appraisal

\begin{tabular}{|c|c|c|c|c|c|c|c|c|}
\hline & & & & & & aisa & & \\
\hline PORTES [55] & Qualitative, retrospective & Brazil & $\begin{array}{l}\text { Urban primary } \\
\text { healthcare units in a } \\
\text { medium-sized } \\
\text { municipality; municipal } \\
\text { programme } \\
\text { coordinator, and senior } \\
\text { health professionals } \\
\text { trained on smoking } \\
\text { cessation or local } \\
\text { managers }\end{array}$ & $\begin{array}{l}\text { Tobacco control - } \\
\text { training } \\
\text { healthcare } \\
\text { professionals on } \\
\text { facilitating } \\
\text { treatment \& } \\
\text { prevention } \\
\text { activities } \\
\text { (Furthermore, } \\
\text { interventions on } \\
\text { governmental } \\
\text { level, n.a. to our } \\
\text { studyl }\end{array}$ & +1 & + & + & + \\
\hline Prasodjo [76] & $\begin{array}{l}\text { Mixed-method, factors } \\
\text { derived from qualitative } \\
\text { data lamongst which } \\
\text { participatory action } \\
\text { research) }\end{array}$ & Indonesia & $\begin{array}{l}\text { Rural community; local } \\
\text { institutions (policy } \\
\text { makers, medical staff, } \\
\text { community leaders } \\
\text { and other } \\
\text { stakeholders) }\end{array}$ & $\begin{array}{l}\text { Post-partum smoke } \\
\text { ('Sei') traditions - } \\
\text { Behavioural } \\
\text { change } \\
\text { communication } \\
\text { campaign } \\
\text { targeting } \\
\text { household air } \\
\text { pollution }\end{array}$ & + & - & \pm & \pm \\
\hline ROSATI [83] & $\begin{array}{l}\text { Mixed-methods, factors } \\
\text { derived from qualitative } \\
\text { data }\end{array}$ & Thailand & $\begin{array}{l}\text { Urban family setting; } \\
\text { health educators } \\
\text { towards families }\end{array}$ & $\begin{array}{l}\text { Tobacco, alcohol } \\
\text { and other } \\
\text { substance abuse } \\
\text { prevention, sex } \\
\text { education }\end{array}$ & \pm 1 & \pm & \pm & \pm \\
\hline SoDHI [59] & $\begin{array}{l}\text { Mixed-methods, factors } \\
\text { derived from qualitative } \\
\text { data }\end{array}$ & Malawi & $\begin{array}{l}30 \text { urban and rural, } \\
\text { government-funded } \\
\text { and non-government } \\
\text { funded health centres; } \\
\text { primary healthcare } \\
\text { workers: clinical } \\
\text { officers, medical } \\
\text { assistants, and nurses }\end{array}$ & $\begin{array}{l}\text { Train-the-trainer on } \\
\text { guideline use for } \\
\text { providing } \\
\text { integrated } \\
\text { primary lung } \\
\text { healthcare }\end{array}$ & \pm 1 & \pm & \pm & + \\
\hline$X_{I A O}[68]$ & $\begin{array}{l}\text { Mixed-method, factors } \\
\text { concerned qualitative } \\
\text { data }\end{array}$ & China & $\begin{array}{l}41 \text { Hospital across the } \\
\text { country, the majority } \\
\text { from a tobacco control } \\
\text { network; medical } \\
\text { doctors and directors }\end{array}$ & $\begin{array}{c}\text { Smoke-free } \\
\text { hospitals }\end{array}$ & \pm 1 & - & $?$ & + \\
\hline Ziedonis [69] & Qualitative & China & $\begin{array}{l}\text { Hospital-based mental } \\
\text { health centre; } \\
\text { personnel and patients }\end{array}$ & $\begin{array}{c}\text { Smoke-free } \\
\text { hospitals }\end{array}$ & +1 & - & $?$ & \pm \\
\hline
\end{tabular}

Studies were prospective unless otherwise indicated. Rv: relevance; R: reliability; V: validity; A: applicability to a wider public health context. $\mathrm{RCT}=$ randomised controlled trial. Scored in appraisal as: +: high; \pm : medium; -: low; ?: unclear. Relevance '1': Evaluation of implementation was a primary outcome of the article. Articles with matching footnote indicators are from the same study. \#: findings from AGHI et al. were excluded from the analysis, as PAWAR et al. based their findings on the same study data and had higher appraisal scores. NAGLER et al. based findings on a different study data (pilot study) and was included. ${ }^{+}$: findings from both studies were included as these were based on different study data. 


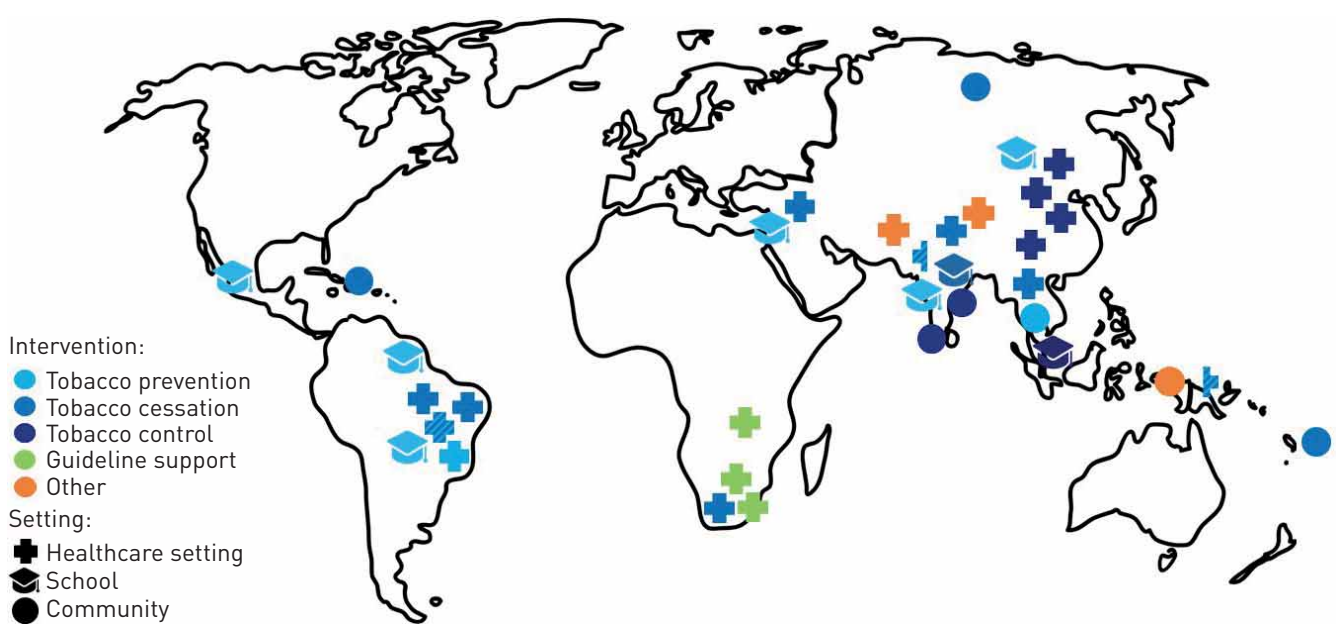

FIGURE 3 Study settings and interventions. Symbols with two colours indicate the study covered both interventions. Half a symbol means half of the study was conducted in this setting and the other half in another setting.

"Compatibility" was another factor with a high level of evidence, coded 48 times across 23 articles. Categorised in the subdomain "Implementation Climate" (domain "Inner setting"), compatibility is defined as the degree of fit between meaning and values attached to the innovation and of the involved individuals, and how the innovation fits with existing workflows and systems [18]. Implementation success was often attributed to embedding interventions into local, existing infrastructures (e.g. the primary care infrastructure), carried out by people in already established networks (e.g. community health workers), and when aligned with local cultural values. This can, for example, be achieved in highly participant-centred interventions. In one study it was stated: "Perhaps the most important lesson was eventually letting go of some of our own techniques and agendas and allowing an indigenous culture to develop their own program." The local participants developed their own programme and implementation strategy in this study, aligned with their local context and, hence, implementation was highly successful [85].

The second important subdomain in the domain "Inner setting" was "Readiness for implementation" (coded 76 times across 32 articles), of which "Access to knowledge and information" (28 times, 22 articles) and "Available resources" (37 times, 21 articles) were defining factors. Studies generally reported the lack of these factors as implementation barriers. Particularly training in knowledge and skills (e.g. knowledge on risks to lung health or motivational interviewing skills) were reported as insufficient, including lack of access to educational materials. The most commonly lacking resources were time and personnel. Other notable lacking resources were limited physical space (such as crowded consultation rooms), insufficient materials (medication, equipment) or assets (electricity). Funding to overcome these barriers was often not feasible, but authors reported that the (lack of) resources should always be considered in the implementation strategy. Where possible, adaptations can then be made accordingly.

Another notable factor was understanding and accurately prioritising on the "Needs of local users" ("Outer setting"). For example, deliverers in one study realised that Chinese parents did not necessarily feel a need for smoking cessation. They also recognised the parents' need for connecting with their child (and children had a unique position in the Chinese one-child families). Deliverers then educated the children on smoking and cessation, which eventually helped to motivate their parents to quit [66]. Level of evidence was also high for "Cosmopolitanism" (networks of the organisation with external organisations; "Outer setting") and "Networks and Communications" ("Inner setting").

Notably, all factors appeared strongly interrelated; e.g. engaged stakeholders could provide adequate knowledge about the needs of those served by the organisation, which could improve compatibility, which in turn could increase the perceived advantage of the intervention. Also, when comparing the implementation factors and their level of evidence across the geographical regions, findings were highly similar. We compared Latin America, Africa, and Asia (China and India were considered both individually and as part of Asia). The Middle East $(n=2)$ and Oceania $(n=1)$ were not considered because of the small number of studies. Only for China there was a notable difference; factors related to the "Outer setting" (e.g. "External policies and incentives") were reported less frequently compared with the other regions.

To facilitate future implementors in the translation of the comprehensive overview of all factors to practice, we summarised the factors in a practical, simplified and manageable implementation tool (figure 5 


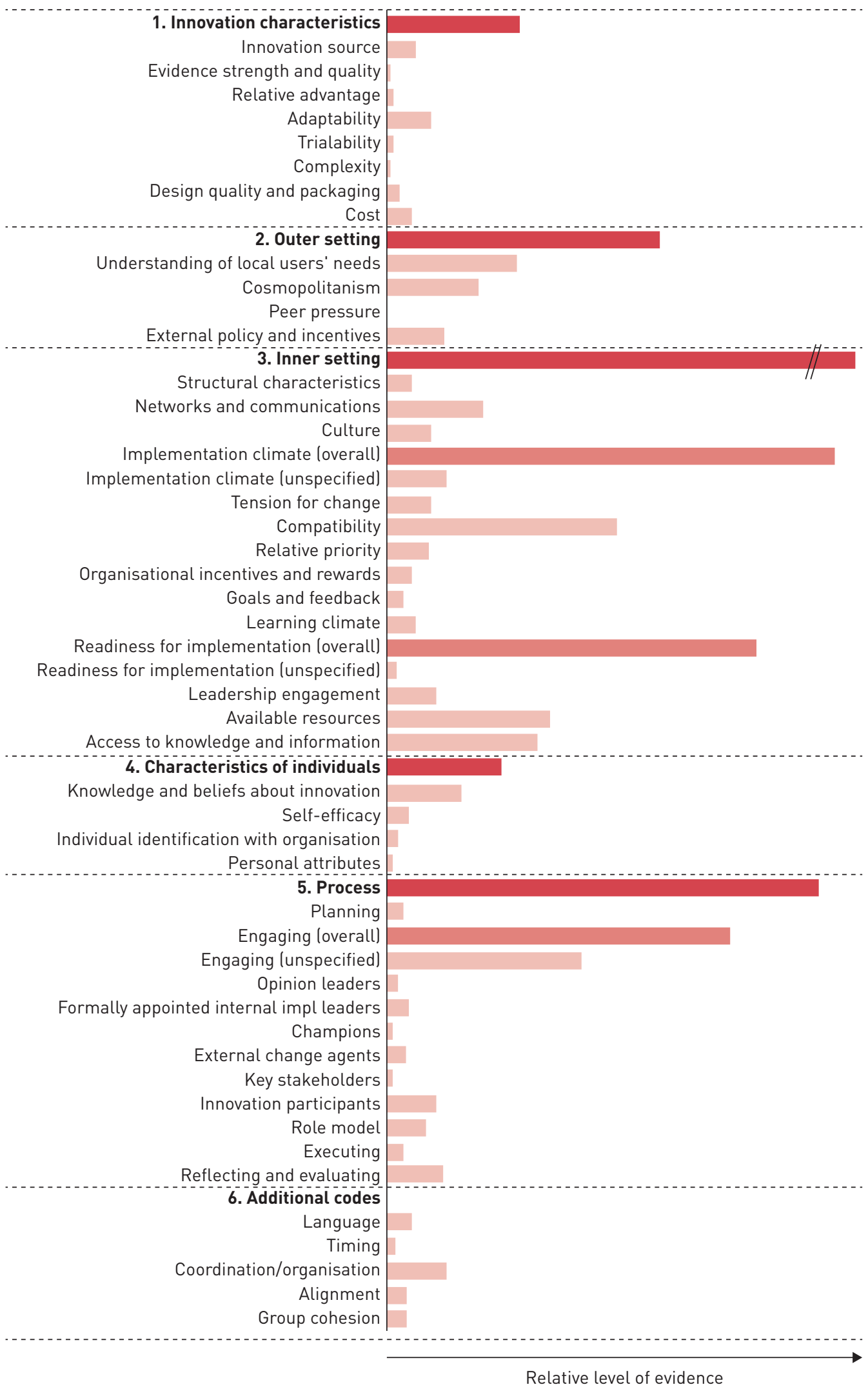

FIGURE 4 Full overview of implementation factors per domain, and the relative level of evidence for the factor. 


\begin{tabular}{|c|c|c|}
\hline Key factor & Description & How to address factor\# (possible approaches) \\
\hline $\begin{array}{l}\text { Engage influential } \\
\text { stakeholders }\end{array}$ & $\begin{array}{l}\text { Identify the influential stakeholders (e.g. } \\
\text { decision makers, community members) } \\
\text { and develop an engagement strategy. }\end{array}$ & $\begin{array}{l}\text { Create a sense of ownership for stakeholders using a community- } \\
\text { based, participatory approach. Invest in establishing trust. }\end{array}$ \\
\hline $\begin{array}{l}\text { Understand local users' } \\
\text { needs }\end{array}$ & $\begin{array}{l}\text { Explore and accurately prioritise the } \\
\text { needs of intended users; understand } \\
\text { barriers and facilitators to meet the needs. }\end{array}$ & $\begin{array}{l}\text { Explore the local context and needs by a team including local } \\
\text { members through a rapid appraisal. See also possible approaches } \\
\text { for how to address "Engage influential stakeholders" }\end{array}$ \\
\hline $\begin{array}{l}\text { Secure necessary } \\
\text { resources }\end{array}$ & $\begin{array}{l}\text { Secure sufficient resources for the } \\
\text { implementation process and ongoing } \\
\text { operations. }\end{array}$ & $\begin{array}{l}\text { If unfeasible, address the lack of resources by adjusting the } \\
\text { intervention and/or delivery strategy accordingly. (Ideally, this should } \\
\text { go in parallel with investing in strengthening the health system.) }\end{array}$ \\
\hline $\begin{array}{l}\text { Facilitate access to } \\
\text { knowledge and information }\end{array}$ & $\begin{array}{l}\text { Enable easy access to digestible } \\
\text { knowledge and information about the } \\
\text { intervention and how to use it. }\end{array}$ & $\begin{array}{l}\text { Organise educational meetings, conduct outreach, facilitate audit- and } \\
\text { feedback moments. }\end{array}$ \\
\hline Ensure compatibility & $\begin{array}{l}\text { Ensure compatibility between the local } \\
\text { (cultural and logistical) context and the } \\
\text { intervention and delivery strategy. }\end{array}$ & $\begin{array}{l}\text { Embed intervention in the existing (political, health) infrastructure by } \\
\text { co-developing delivery strategy with local users. See "Understanding } \\
\text { local users' needs", "Engaging influential stakeholders". }\end{array}$ \\
\hline
\end{tabular}

Address and monitor factors throughout entire implementation process: from planning phase to sustained use

FIGURE 5 Free Respiratory Evaluation and Smoke-exposure reduction by primary Health cAre Integrated gRoups (FRESH AIR) Implementation Tool. " : These suggestions are based on the literature specific for interventions targeting chronic respiratory disease in low- and middle-income countries, and on additional, general implementation literature. See Appendix 7 for recommended use of the tool and details on the references.

and appendix 7). The tool contains factors prioritised by their level of evidence and illustrates those factors with examples of how to address them.

\section{Discussion \\ Main results}

In this systematic literature review and meta-synthesis, we identified and weighed factors critical to the implementation of interventions targeting CRD in LMICs. Factors for which the level of evidence was high were: 1) understanding needs of local users; 2) compatibility of the intervention with the local context (such as the political and health infrastructure, or the culture); 3) identification of influential stakeholders and application of engagement strategies; 4) adequate access to knowledge and information (including skills); and 5) sufficient available resources. Additional factors were identified with a lower level of evidence. Most important recommendations for future implementors were compiled in the FRESH AIR Implementation Tool.

\section{Strengths and limitations}

To the best of our knowledge, this systematic review is the first to focus on factors critical to the implementation of diverse CRD-interventions. It focussed on LMICs, precisely where the burden of disease is highest, while evidence is fragmented and often poor for these settings. This review had a rigorous design and conduct, following Cochrane methodology and PRISMA reporting standards [39-41]. Every step was standardised and performed independently by two researchers. Validated tools were applied at each stage $[18,42,43,46]$, with a transparent description of their operationalisation. Moreover, we adopted a comprehensive approach with an extensive search in eight databases with no language/date restrictions. We synthesised real-world evidence from highly diverse settings and countries in the included studies, resulting in a high generalisability of the findings to other settings [86]. In fact, the LMICs in this review were broadly representative of the population distribution across the worlds' continents, among others with many studies conducted in China and India.

However, several relevant types of interventions were underrepresented or even absent in the implementation literature, such as patient education, self-management or pulmonary rehabilitation. Due to the small number of existing studies that focus on such interventions, we were unable to assess whether their implementation factors meaningfully differed from tobacco-related interventions. However, as the desired implementation behaviour is focussed on a similar health goal in similar settings, we assume that there will be at least some overlap in implementation factors. Meanwhile, the high representation of tobacco-related studies in literature remains welcome, with $80 \%$ of the world's smokers living in LMICs [87]. As another limitation, we recognise along with other authors that implementation studies are poorly indexed, and we possibly missed relevant studies [88]. Yet, data saturation was still achieved in the identified factors and the hierarchy of their level of evidence. Notably, absence of evidence (factors not 
reported) should not be interpreted as evidence of absence (factors not important); [47] we could only determine the level of confidence in the importance of factors, for which we relied on the existing evidence.

\section{Comparison to previous literature}

Our findings partly overlap with implementation factors considered important for clean cooking interventions as reported in two reviews $[89,90]$. First, our factors "Compatibility" and "Understanding local users' needs" correspond to "user needs" (e.g. the ability of clean cookstoves to give the food the right taste or save fuel). Second, our factors "Engaging" and "Access to knowledge and information" correspond to "community involvement" and "user training". The authors of these studies similarly observed that barriers could turn into facilitators when these are adequately addressed and vice versa. They also concluded that factors should be addressed simultaneously because they all interrelate. The overlap between their findings and ours may not be surprising, as clean cooking interventions similarly target CRD in LMICs. Possibly, this supports the assumption mentioned earlier that implementation factors would not differ substantially for those chronic lung health interventions in LMICs that have not yet been studied.

Implementation is a relatively unexplored topic in LMICs, and we predominantly relied on qualitative articles. Qualitative studies allow for a deeper understanding of the how, what and why of implementation processes [91]. As opposed to in quantitative studies, the concept "high level of evidence" cannot be quantified or tested on significance in qualitative studies. Therefore, a combination of qualitative with quantitative (mixed-method) evidence would be highly welcome; such studies are still largely unavailable. The need for more high-quality implementation evidence for LMICs has been highlighted repeatedly [25, 34-37, 92]. Systematic reviews are particularly scarce.

\section{Interpretation and implications for implementation initiatives}

Our findings could serve future implementation initiatives, especially those initiatives targeting CRD in LMICs. To facilitate the design of effective implementation strategies for CRD-related interventions, we have developed a comprehensive overview of all implementation factors, their level of evidence and examples of how they played a role in the included studies (appendix 6). In addition, we translated factors from the comprehensive overview into a more pragmatic and hands-on tool for practice (figure 5). Throughout the implementation process, implementors should address these factors in their strategy, and should continuously monitor the effectiveness of their strategy to improve it accordingly [93].

Therefore, awareness of the implementation factors requires additional evidence on how to adequately address them [93, 94]. A suggestion for how to address the two critical factors "Compatibility" and "Understanding local users' needs", is developing, testing and disseminating "homegrown" interventions [95]. This was done in another FRESH AIR study by conducting an initial explorative mixed-method rapid assessment of the local context [96]. The results of this assessment informed implementation strategies for improved cookstove interventions in Uganda, Vietnam and Kyrgyzstan [97]. First, the context assessment revealed that communities and their health workers poorly understood the risk of household air pollution and therefore felt no need for change. Hence, the intervention was preceded by an awareness-raising programme. Second, the rapid assessment helped to identify the relevant influential stakeholders in the settings (e.g. village leaders, district health officers). These stakeholders were then involved in the design of the implementation strategy, which ensured high compatibility of the strategy with the local reality and "Engaged the stakeholders" (the third critical factor) for the subsequent delivery [98].

A creative example of addressing the fourth critical factor, "Access to knowledge and information and skilled staff”, could be introducing task-sharing between physician and non-physician health workers. This proved to be effective in lowering blood pressure in LMICs [99]. The fifth critical factor, "Resource availability", can be particularly challenging to address. One included study reported that workshop facilitators overcame the barrier of transportation costs by ride sharing and delivering several sessions per visit to reduce the number of visits [63]. Reducing the impact of the lack of resources generally requires innovative system strengthening [16].

Overall, opinions on how to address implementation factors most effectively turned out to be highly heterogeneous among experts [100]; additional how-to evidence is required.

\section{Implications for implementation research}

Studies that systematically evaluate approaches of how to address implementation factors are needed to provide solid and detailed evidence for future initiatives. We are currently working on part two of this review, which focuses on the implementation of clean cooking interventions. However, we argue that future studies should also focus on topics beyond tobacco and clean cooking, such as personalised asthma 
action plans or pulmonary rehabilitation [87]. The studies included in this review consistently missed economic evaluations, so we recommend future studies to also include those [101]. Furthermore, results from the critical appraisal of the studies showed that research quality could generally benefit from more standardised methods and more structured reporting of, for example, context characteristics, implementation strategies and their conduct. These and additional recommendations are further outlined in an article on improving health-care provider practices for LMICs [93], and in the STandards for Reporting Implementation Studies [88].

\section{Implications for practice}

Guiding implementation processes by evidence-informed implementation strategies could enhance implementation success. Successful implementation can substantially increase interventions' effectiveness [17]. This could, in turn, optimise the use of already limited resources and decrease the high direct and indirect costs associated with CRD in LMICs $[102,103]$. Above all, implementation success could improve health outcomes.

\section{Conclusion}

In this study, we systematically searched the literature for factors critical to the successful implementation of lung health interventions. We meta-synthesised the factors' level of evidence and developed an implementation tool for practice. Priority for future implementors should be to understand needs of local users, ensure compatibility of the intervention with the local context, engage influential stakeholders, facilitate adequate access to knowledge and information, and secure sufficient resources. Use of the FRESH AIR Implementation Tool could facilitate policymakers, non-governmental organisations, practitioners, researchers and community members to design evidence-based, tailored implementation strategies to enhance implementation success. This could hence optimise the use of already scarce resources and, ultimately, improve health outcomes.

Acknowledgements: We thank Asel Arykbaev and Marise Kasteleyn, Leiden University Medical Center (LUMC), for contributing to the development of the search and the research protocol, and medical librarians Karin van der Hoorn and Jan Schoones (LUMC) for their support in building the search. Also, we thank Susanne McLean, University of Edinburgh, for building the search in the Global Health database. Lastly, a special thanks to Loran Nordgren, Northwestern University, for his helpful conceptual input from a social psychology perspective.

Author contributions: E.A. Brakema was lead researcher; E.A. Brakema and D. Vermond designed the study and developed the protocol, including the search (helped by those acknowledged). They performed the screening process, data extraction and analysis under supervision of R.M.J.J. van der Kleij and N.H. Chavannes. E.A. Brakema wrote the manuscript, R.M.J.J. van der Kleij reviewed it at each stage. H. Pinnock and D. Vermond provided input throughout the process. All others reviewed the manuscript and helped translating the findings to meaningful practical recommendations. All authors approved the final version.

Conflict of interest: None declared.

Support statement: This study was funded by the EU Research and Innovation programme Horizon2020 (Health, Medical research and the challenge of ageing) under grant agreement number 680997. Funding information for this article has been deposited with the Crossref Funder Registry.

\section{References}

1 World Health Organization. Chronic respiratory diseases. www.who.int/respiratory/en/ Data last accessed: January 9, 2020.

2 World Health Organization. Global Surveillance, prevention and control of chronic respiratory diseases: a comprehensive approach, 2007. www.who.int/gard/publications/GARD_Manual/en/ Date last accessed: January 9, 2020.

3 Salvi S. The silent epidemic of COPD in Africa. Lancet Glob Health 2015; 3: e6-e7.

4 FitzGerald JM, Al Efraij K. Asthma in low-income and middle-income countries: an urgent call to action. Thorax 2018; 73: 898-899.

5 Halpin DMG, Celli BR, Criner GJ, et al. It is time for the world to take COPD seriously: a statement from the GOLD board of directors. Eur Respir J 2019; 54: 1900914

6 Pleasants RA, Riley IL, Mannino DM. Defining and targeting health disparities in chronic obstructive pulmonary disease. Int J Chron Obstruct Pulmon Dis 2016; 11: 2475-2496.

7 Townend J, Minelli C, Mortimer K, et al. The association between chronic airflow obstruction and poverty in 12 sites of the multinational BOLD study. Eur Respir J 2017; 49: 1601880.

8 Martinez FD. Early-life origins of chronic obstructive pulmonary disease. N Engl J Med 2016; 375: 871-878.

9 Brakema EA, van Gemert FA, van der Kleij R, et al. COPD's early origins in low-and-middle income countries: what are the implications of a false start? NPJ Prim Care Respir Med 2019; 29: 6.

10 Sood A, Assad NA, Barnes PJ, et al. ERS/ATS workshop report on respiratory health effects of household air pollution. Eur Respir J 2018; 51: 1700698.

11 Beran D, Zar HJ, Perrin C, et al. Burden of asthma and chronic obstructive pulmonary disease and access to essential medicines in low-income and middle-income countries. Lancet Respir Med 2015; 3: 159-170. 
12 Gordon SB, Bruce NG, Grigg J, et al. Respiratory risks from household air pollution in low and middle income countries. Lancet Respir Med 2014; 2: 823-860.

13 Torres-Duque CA. Poverty cannot be inhaled and it is not a genetic condition. How can it be associated with chronic airflow obstruction? Eur Respir J 2017; 49: 1700823.

14 Thomas E, Wickramasinghe K, Mendis S, et al. Improved stove interventions to reduce household air pollution in low and middle income countries: a descriptive systematic review. BMC Public Health 2015; 15: 650.

15 Dogar O, Elsey H, Khanal S, et al. Challenges of integrating tobacco cessation interventions in TB programmes: Case studies from Nepal and Pakistan. Journal of Smoking Cessation 2016; 11: 108-115.

16 Mendis S, Al Bashir I, Dissanayake L, et al. Gaps in capacity in primary care in low-resource settings for implementation of essential noncommunicable disease interventions. Int J Hypertens 2012; 2012: 584041.

17 Durlak JA, DuPre EP. Implementation matters: a review of research on the influence of implementation on program outcomes and the factors affecting implementation. Am J Commun Psychol 2008; 41: 327-350.

18 Damschroder LJ, Aron DC, Keith RE, et al. Fostering implementation of health services research findings into practice: a consolidated framework for advancing implementation science. Implement Sci 2009; 4: 50.

19 Burnes B. Emergent change and planned change: competitors or allies?: The case of XYZ construction. Int J Oper Prod Manage 2004; 24: 886-902.

20 Bensch G, Grimm M, Peters J. Why do households forego high returns from technology adoption? Evidence from improved cooking stoves in Burkina Faso. J Econ Behav Organ 2015; 116: 187-205.

21 Clark S, Carter E, Shan M, et al. Adoption and use of a semi-gasifier cooking and water heating stove and fuel intervention in the Tibetan Plateau, China. Environ Res Lett 2017; 12: 11.

22 El Tayeb Muneer S, Mukhtar Mohamed el W. Adoption of biomass improved cookstoves in a patriarchal society: an example from Sudan. Sci Total Environ 2003; 307: 259-266.

23 Jagger P, Jumbe C. Stoves or sugar? Willingness to adopt improved cookstoves in Malawi. Energy policy 2016; 92 : 409-419.

24 Namagembe A, Muller N, Scott LM, et al. Factors influencing the acquisition and correct and consistent use of the top-lit updraft cookstove in Uganda. (Special Issue: Advancing communication and behavior change strategies for cleaner cooking.). J Health Commun Int Perspect 2015; 20: Suppl. 1, 76-83.

25 Brakema EA, van der Kleij RM, Vermond D, et al. Let's stop dumping cookstoves in local communities. It's time to get implementation right. NPJ Prim Care Respir Med 2020; 30: 3.

Peters DH, Adam T, Alonge O, et al. Implementation research: what it is and how to do it. BMJ 2013; 347: f6753. Rogers E. Diffusion of Innovations. 5th Edn. New York, Free Press, 2003.

Grol R, Grimshaw J. From best evidence to best practice: effective implementation of change in patients' care. Lancet 2003; 362: 1225-1230.

29 Baker R, Camosso-Stefinovic J, Gillies C, et al. Tailored interventions to address determinants of practice. Cochrane Database Syst Rev 2015; 4: CD005470.

30 Mackay J. The role of research on the development and implementation of policy. Nicotine Tob Res 2013; 15: 757-760.

31 Ahmad N, Boutron I, Dechartres A, et al. Geographical representativeness of published and ongoing randomized controlled trials. The example of: tobacco consumption and HIV infection. PLoS One 2011; 6: e16878.

32 Siddiqi K, Newell J, Robinson M. Getting evidence into practice: what works in developing countries? Int J Qual Health Care 2005; 17: 447-454.

33 Langer A, Diaz-Olavarrieta C, Berdichevsky $\mathrm{K}$, et al. Why is research from developing countries underrepresented in international health literature, and what can be done about it? Bull World Health Organ 2004; 82: 802-803.

34 Chamberlain C, O’Mara-Eves A, Porter J, et al. Psychosocial interventions for supporting women to stop smoking in pregnancy. Cochrane Database Syst Rev 2017; 2: CD001055.

35 Martin K, Mullan Z, Horton R. Overcoming the research to policy gap. Lancet Glob Health 2019; 7: Suppl. 1, S1-S2.

36 Ridde V. Need for more and better implementation science in global health. BMJ Glob Health 2016; 1: e000115.

37 Singh SJ, Halpin DMG, Salvi S, et al. Exercise and pulmonary rehabilitation for people with chronic lung disease in LMICs: challenges and opportunities. Lancet Respir Med 2019; 7: 1002-1004.

38 Cragg L, Williams S, Chavannes NH. FRESH AIR: an implementation research project funded through Horizon 2020 exploring the prevention, diagnosis and treatment of chronic respiratory diseases in low-resource settings. NPI Prim Care Respir Med 2016; 26: 16035.

39 Higgins JPT, Green S. Cochrane Handbook for Systematic Reviews of Interventions Version 5.1.0. https://training. cochrane.org/handbook/archive/v5.1/ Date last accessed: January 9, 2020; date last updated: March 20, 2011.

40 Noyes J, Booth A, Cargo M, et al. Chapter 21: Qualitative evidence. In: J Higgins, J Thomas, J Chandler, et al., eds. Cochrane; Cochrane Handbook for Systematic Reviews of Interventions version 60. Hoboken, Wiley, 2019.

41 Moher D, Liberati A, Tetzlaff J, et al. Preferred reporting items for systematic reviews and meta-analyses: the PRISMA statement. BMJ 2009; 339: b2535.

42 Rosella L, Bowman C, Pach B, et al. The development and validation of a meta-tool for quality appraisal of public health evidence: Meta Quality Appraisal Tool (MetaQAT). Public Health 2016; 136: 57-65.

43 Critical Appraisal Skills Programme. CASP (Qualitative and Cohort) Checklist. Date last accessed: July 1, 2017. Date last updated: 2017.

44 Damschroder LJ, Lowery JC. Evaluation of a large-scale weight management program using the Consolidated Framework for Implementation Research (CFIR). Implement Sci 2013; 8: 51.

45 Moullin JC, Sabater-Hernández D, Fernandez-Llimos F, et al. A Systematic Review of Implementation Frameworks of Innovations in Healthcare and Resulting Generic Implementation Framework. Health Res Policy Syst 2015; 13: 16.

46 Lewin S, Glenton C, Munthe-Kaas H, et al. Using qualitative evidence in decision making for health and social interventions: an approach to assess confidence in findings from qualitative evidence syntheses (GRADE-CERQual). PLoS Med 2015; 12: e1001895.

47 Dixon-Woods M, Agarwal S, Young B. Integrative approaches to qualitative and quantitative evidence: NHS Health Development Agency. London, Health Development Agency, 2004. 

datahelpdesk.worldbank.org/knowledgebase/articles/906519-world-bank-country-and-lending-groups Date last accessed: July 1, 2019; date last updated: 2017.

49 Aghi M, Nagler EM, Lando H, et al. Training lay interventionists to support tobacco cessation among teachers in India. Int J Health Promot Educ 2016; 54: 304-317.

50 Pawar P, Nagler E, Gupta P, et al. Tracking intervention delivery in the 'Tobacco-Free Teachers/Tobacco-Free Society’ program, Bihar, India. Health Educ Res 2015; 30: 731-741.

51 Castaldelli-Maia JM, da Silva NR, Campos MRD, et al. Implementing evidence-based smoking cessation treatment in psychosocial care units (CAPS) in Brazil. Int J Soc Psychiatry 2017; 63: 669-673.

52 Cruvinel E, Richter KP, Bastos RR, et al. Screening and brief intervention for alcohol and other drug use in primary care: associations between organizational climate and practice. Addict Sci Clin Pract 2013; 8: 4.

53 Medeiros PFP, Cruz JI, Schneider DR, et al. Process evaluation of the implementation of the Unplugged Program for drug use prevention in Brazilian schools. Subst/ Abus Treatment Prev Pol 2016; 11: 11.

54 Pereira AP, Paes AT, Sanchez ZM. Factors associated with the implementation of programs for drug abuse prevention in schools. Rev Saude Publica 2016; 50: 44.

55 Portes LH, Campos EMS, Teixeira MTB, et al. Actions geared to tobacco control: a review of their implementation in Primary Health Care. Cien Saude Colet 2014; 19: 439-448.

56 Ossip DJ, Diaz S, Quinones Z, et al. Lessons Learned from Twelve Years of Partnered Tobacco Cessation Research in the Dominican Republic. J Smok Cessat 2016; 11: 99-107.

57 Marsiglia F, Booth J, Ayers S, et al. Short-term effects on substance use of the keepin' it real pilot prevention program: linguistically adapted for youth in Jalisco, Mexico. Prev Sci 2014; 15: 694-704.

58 Ishaak F, de Vries NK, van der Wolf K. Test implementation of a school-oriented drug prevention program "Study without Drugs": pre- and post-testing for effectiveness. BMC Public Health 2014; 14: 590.

59 Sodhi S, Banda H, Kathyola D, et al. Supporting middle-cadre health care workers in Malawi: lessons learned during implementation of the PALM PLUS package. (Special Issue: Uptake and impact of research for evidence-based practice: lessons from the Africa Health Systems Initiative's research component.). BMC Health Serv Res 2014; 14: Suppl. 1.

60 Bheekie A, Buskens I, Allen S, et al. The Practical Approach to Lung Health in South Africa (PALSA) intervention: respiratory guideline implementation for nurse trainers. Int Nurs Rev 2006; 53: 261-268.

61 Malan Z, Mash R, Everett-Murphy K. Qualitative evaluation of primary care providers experiences of a training programme to offer brief behaviour change counselling on risk factors for non-communicable diseases in South Africa. BMC Fam Pract 2015; 16: 101.

62 Mash B, Rhode H, Pather M, et al. Evaluation of the asthma guideline implementation project in the Western Cape, South Africa. Curr Allergy Clin Immunol 2010; 23: 154-161.

63 Bteddini D, Afifi R, Haddad P, et al. Process evaluation and challenges of implementation of a school based waterpipe tobacco smoking prevention program for teens in Lebanon. Tob Prev Cessat 2017; 3: 11.

64 Asfar T, Ward KD, Al-Ali R, et al. Building Evidence-Based Tobacco Treatment in the Eastern Mediterranean Region: Lessons Learned by the Syrian Center for Tobacco Studies. J Smok Cessat 2016; 11: 116-123.

65 Aldinger C, Zhang XW, Liu LQ, et al. Strategies for implementing Health-Promoting Schools in a province in China. Promot Educ 2008; 15: 24-29.

66 Aldinger C, Zhang XW, Liu LQ, et al. Changes in attitudes, knowledge and behavior associated with implementing a comprehensive school health program in a province of China. Health Educ Res 2008; 23: 1049-1067.

67 Wang JF, Ma SJ, Mei CZ, et al. Exploring barriers to implementation of smoking policies: A qualitative study on health professionals from three county-level hospitals. Biomed Environ Sci 2008; 21: 257-263.

68 Xiao D, Wang C, Chen $\mathrm{H}$, et al. Making hospitals in China smoke-free: a prospective study of implementing the new standard. Nicotine Tob Res 2013; 15: 2076-2080.

69 Ziedonis DM, Wang X, Li T, et al. Addressing tobacco through organizational change in a hospital-based mental health center in china: The intervention and lessons learned in a pilot implementation project. J Dual Diagn 2012; 8: 148-157.

70 Chatterjee N, Patil D, Kadam R, et al. The tobacco-free village program: helping rural areas implement and achieve goals of tobacco control policies in India. Glob Health Sci Pract 2017; 5: 476-485.

71 Goenka S, Tewari A, Arora M, et al. Process evaluation of a tobacco prevention program in Indian schools--methods, results and lessons learnt. Health Educ Res 2010; 25: 917-935.

72 Nagler EM, Pednekar MS, Viswanath K, et al. Designing in the social context: using the social contextual model of health behavior change to develop a tobacco control intervention for teachers in India. Health Educ Res 2013; 28: 113-129.

73 Nichter M, Nichter M, Muramoto M. Project Quit Tobacco International: laying the groundwork for tobacco cessation in low- and middle-income countries. Asia Pac J Public Health 2010; 22: 3 Suppl, 181S-188S.

74 Perry C, Stigler M, Arora M, et al. Prevention in translation: tobacco use prevention in India. Health Promot Pract 2008; 9: 378-386.

75 Persai D, Panda R, Gupta A. Examining implementation of tobacco control policy at the district level: a case study analysis from a high burden state in India. Adv Prev Med 2016; 2016: 4018023.

76 Prasodjo R, Musadad DA, Muhidin S, et al. Advocate program for healthy traditional houses, Ume Kbubu, in a Timor community: preserving traditional behavior and promoting improved health outcomes. J Health Commun 2015; 20: Suppl. 1, 10-19.

77 Melson E, Bridle C, Markham W. Pragmatic pilot cluster randomised control trial of a school-based peer-led anti-smoking intervention for 13-14 year olds in Malaysia: Process evaluation. Health Educ 2017; 117: 599-616.

78 Elsey H, Khanal S, Manandhar S, et al. Understanding implementation and feasibility of tobacco cessation in routine primary care in Nepal: a mixed methods study. Implement Sci 2016; 11: 104.

79 Mehanni S, Jha D, Kumar A, et al. Implementing a quality improvement initiative for the management of chronic obstructive pulmonary disease in rural Nepal. BMJ Open Qual 2019; 8: e000408.

80 Khan MA, Khan MA, Walley JD, et al. Feasibility of delivering integrated COPD-asthma care at primary and secondary level public healthcare facilities in Pakistan: a process evaluation. BJGP Open 2019; 3: bjgpopen18X101632. 
82 Assanangkornchai S, Balthip Q, Edwards JG. Implementing the Alcohol, Smoking, Substance Involvement Screening Test and linked brief intervention service in primary care in Thailand. J Public Health (Oxf) 2014; 36: 443-449.

83 Rosati MJ, Cupp PK, Chookhare W, et al. Successful implementation of Thai Family Matters: strategies and implications. Health Promot Pract 2012; 13: 355-363.

84 Vitavasiri C, Pausawasdi S. Implementation of 100\% smoke-free hospital in Thailand. J Med Assoc Thai 2010; 93: $860-864$.

85 Groth-Marnat G, Leslie S, Renneker M. Tobacco control in a traditional Fijian village: Indigenous methods of smoking cessation and relapse prevention. Soc Sci Med 1996; 43: 473-477.

86 Luyckx VA, Reis A, Maher D, et al. Highlighting the ethics of implementation research. Lancet Glob Health 2019; 7: e1170-e1171.

87 The Lancet Respiratory M. Smoking cessation efforts should target LMICs. Lancet Respir Med 2019 ; 7: 721.

88 Pinnock H, Barwick M, Carpenter CR, et al. Standards for Reporting Implementation Studies (StaRI) statement. BMJ 2017; 356: i6795.

89 Puzzolo E, Pope D, Stanistreet D, et al. Clean fuels for resource-poor settings: A systematic review of barriers and enablers to adoption and sustained use. Environ Res 2016; 146: 218-234.

90 Rehfuess EA, Puzzolo E, Stanistreet D, et al. Enablers and barriers to large-scale uptake of improved solid fuel stoves: a systematic review. Environ Health Perspect 2014; 122: 120-130.

91 Greenhalgh T, Taylor R. Papers that go beyond numbers (qualitative research). BMJ 1997; 315: 740-743.

92 Movsisyan A, Arnold L, Evans R, et al. Adapting evidence-informed complex population health interventions for new contexts: a systematic review of guidance. Implement Sci 2019; 14: 105.

93 Rowe AK, Rowe SY, Peters DH, et al. Effectiveness of strategies to improve health-care provider practices in low-income and middle-income countries: a systematic review. Lancet Glob Health 2018; 6: e1163-e1175.

94 Daivadanam M, Ingram M, Sidney Annerstedt K, et al. The role of context in implementation research for non-communicable diseases: Answering the 'how-to' dilemma. PLoS One 2019; 14: e0214454.

95 Ward KD. Tobacco intervention research in low- and middle-income countries: lessons learned and future directions. J Smok Cessat 2016; 11: 61-64.

96 Beebe J. Basic Concepts and Techniques of Rapid Appraisal. Hum Organ 1995; 54: 42-51.

97 van Gemert F, de Jong C, Kirenga B, et al. Effects and acceptability of implementing improved cookstoves and heaters to reduce household air pollution: a FRESH AIR study. NPJ Prim Care Respir Med 2019; $29: 32$.

98 Vardavas CI, Kyriakos CN, Fernandez E, et al. H2020 funding for respiratory research: scaling up for the prevention and treatment of lung diseases. Eur Respir J 2019; 54: 1901417.

99 Anand TN, Joseph LM, Geetha AV, et al. Task sharing with non-physician health-care workers for management of blood pressure in low-income and middle-income countries: a systematic review and meta-analysis. Lancet Glob Health 2019; 7: e761-e771.

100 Waltz TJ, Powell BJ, Fernandez ME, et al. Choosing implementation strategies to address contextual barriers: diversity in recommendations and future directions. Implement Sci 2019; 14: 42.

101 Powell BJ, Fernandez ME, Williams NJ, et al. Enhancing the impact of implementation strategies in healthcare: a research agenda. Front Public Health 2019; 7: 3.

102 Brakema EA, Tabyshova A, van der Kleij R, et al. The socioeconomic burden of chronic lung disease in low-resource settings across the globe - an observational FRESH AIR study. Respir Res 2019; 20: 291.

103 Horvath I, Barry M, Brusselle G, et al. The European Respiratory Society's 10 Principles for Lung Health. Eur Respir J 2018; 52: 1801373. 